\title{
田
}

\section{MANIFESTAÇÕES RELIGIOSAS DOS/AS ASSISTENTES SOCIAIS: ALGUNS APONTAMENTOS A PARTIR DE MAX WEBER}

\author{
Religious manifestations of social workers: some notes from Max Weber
}

\author{
Claudia Neves da Silva* \\ https://orcid.org/0000-0003-1337-4741
}

\begin{abstract}
RESUMO
Nos últimos anos constata-se a investida do pensamento conservador em todos os campos - político, social, econômico, cultural - comprovando sua força nos diferentes grupos e segmentos sociais. E entre os profissionais do Serviço Social também verifica-se esta reatualização do conservadorismo em sua relação com os usuários das políticas sociais e demais profissionais. Assim, há o interesse de estudar as manifestações religiosas e suas repercussões no exercício profissional do assistente social. Para investigação e análise dos dados, o arcabouço teórico - metodológico foi construído a partir das contribuições de Max Weber, que se dedicou a perscrutar a sociedade burguesa ocidental e a consolidação de uma ética racional capitalista. Como resultado, foi verificado que os assistentes sociais em situações diversas têm se baseado no pensamento religioso para compreender as questões à sua volta. Diante do crescimento do fenômeno religioso e da intolerância religiosa, torna-se importante discutir e tratar este tema, visando garantir o que determina o Artigo $5^{\circ}$ da Constituição brasileira.
\end{abstract}

\section{PALAVRAS-CHAVE}

Serviço Social. Max Weber. Religião. Exercício Profissional

\section{ABSTRACT}

In recent years, there has been an influx of conservative thinking in all fields - political, social, economic and cultural - attesting to its strength in different social groups and segments. And among Social Worker professionals, there is also a re-visualization of conservatism, in its relationship with users of social policies and other professionals. Thus, there is the interest of studying the religious manifestations and their repercussions in the professional practice of the Social Worker. For the investigation and analysis of the data, the theoretical - methodological framework was constructed from the contributions of Max Weber, who was dedicated to examining western bourgeois society and the consolidation of a rational capitalist ethic. As a result, it has been found that Social Workers in diverse situations have relied on religious thinking to understand the issues around them. Faced with the growth of religious phenomena and religious intolerance, it is important to discuss and address this issue, in order to guarantee what is determined by Article 5 of the Brazilian Constitution.

\footnotetext{
* Assistente Social. Pós-Doutora em Serviço Social. Professora do Dpto de Serviço Social e do Programa de Pós-Graduação em Serviço Social e Política Social da Universidade Estadual de Londrina. (UEL, Londrina, Brasil). Rodovia Celso Garcia Cid, PR-445, Km 380, Campus Universitário, Londrina (PR), CEP.: 86057-970. Email: claudianevess@uel.br.
}

DOI 10.22422/temporalis.2020v2on40p182-200 Commons Atribuição 4.0 Internacional (https://creativecommons.org/licenses/by/4.o/deed.pt_BR), que permite copiar e redistribuir o material em qualquer suporte ou formato, bem como adaptar, transformar e criar a partir deste material para qualquer fim, mesmo que comercial. O licenciante não pode revogar estes direitos desde que você respeite os termos da licença.

Temporalis, Brasília (DF), ano 20, n. 40, p. 182-200, jul./dez. 2020. | ISSN 2238-1856 


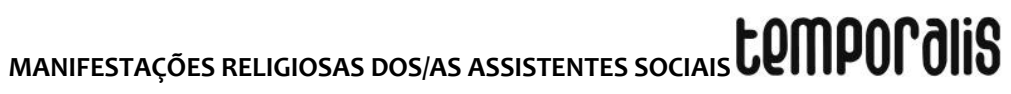

\section{KEYWORDS}

Social Work. Max Weber. Religion. Professional Exercise.

\section{INTRODUÇÃO}

A cada semana constatamos a contraofensiva do conservadorismo nos campos social, econômico, político, cultural e religioso, demonstrando que sempre esteve presente, apenas recuando em alguns momentos e retornando em outros, particularmente nos momentos de crise econômica e política, como a que estamos vivendo atualmente. Em vista disso, nosso interesse voltou-se para entender o conservadorismo, especificamente a religiosidade manifestada nas ações cotidianas do assistente social, ou seja, verificar se e como os valores e princípios religiosos influenciam na atividade junto aos usuários das políticas sociais.

Para entender as questões culturais contemporâneas nos apoiamos em estudiosos que se debruçaram sobre a temática cultura, sociedade e Estado, como Max Weber, que se dedicou a perscrutar a sociedade burguesa ocidental e a consolidação de uma ética racional capitalista, antecipada pela ética calvinista.

A partir de um estudo realizado junto aos profissionais do Serviço Social, cujo objetivo foi estudar as manifestações culturais religiosas e suas repercussões na prática profissional dos assistentes sociais ${ }^{1}$, pudemos verificar que a religiosidade por vezes orienta e dá significado às ações destes profissionais. Contudo, ainda nos inquietava entender como os valores e princípios religiosos dão sentido às ações dos assistente sociais, não obstante a formação profissional fundamentar-se na interlocução com a teoria social crítica, distante de doutrinas religiosas. Assim sendo, interpretamos os dados coletados junto aos assistentes sociais à luz da contribuição de Max Weber.

\section{MAX WEBER E OS ESTUDOS DE RELIGIÃO}

Max Weber é um autor clássico, porque atual. Sua obra, escrita há mais de 100 anos, ainda é necessária e importante para quem tem a intenção de estudar a sociedade moderna e sua multiplicidade e complexidade, tendo em vista que esta sociedade ainda apresenta as mesmas ambiguidades e contradições, e seu objetivo foi tentar entender e analisar os "[...] problemas da racionalização, da secularização, da burocratização das estruturas e dos comportamentos das pessoas como traços específicos da civilização ocidental." (TRAGTENBERG, 1999, p. xii)

Ainda conforme Tragtenberg (1999, p.xvi) "Weber não só se preocupou em analisar como o econômico influiu no social, no político, no religioso, mas também como estes reagem

\footnotetext{
${ }^{1}$ Os resultados da pesquisa poderão ser encontrados nos seguintes artigos: SILVA, C.N.; DUTRA, P.V.; LANZA, F. A Relação entre Manifestações Religiosas e o Exercício Profissional dos Assistentes Sociais: Um Estudo das Contradições e Possibilidades no Norte do Paraná. Sociedade em Debate. Pelotas, 22(2), p. 415 441, 2016. Disponível em: http://revistas.ucpel.tche.br/index.php/rsd/article/view/1420/944. NEGRÃO, L. S.; SILVA, C.N. O exercício profissional e a presença da religião: um estudo de caso a partir do Serviço Social. Revista Brasileira de Iniciação Científica, Itapetininga, v. 4, n. 9, 2017. Disponível em: https://periodicos.itp.ifsp.edu.br/index.php/IC/article/view/696/819.
}

Temporalis, Brasília (DF), ano 20, n. 40, p. 182-200, jul./dez. 2020. | ISSN 2238-1856 
ao econômico. Essa discussão com Marx permite a Weber tornar-se o gande sociólogo das 'superestruturas'”.

A preocupação de Weber concentrava-se na questão metodológica da ciência dos espíritos (sociais, histórica, culturais) ou humanas, erigindo o método de interpretação da realidade social. Seu arcabouço teórico e metodológico possibilita refletir fatos e situações voltadas ao estudo da realidade social e das relações de sociabilidade contemporânea.

Weber teve por objetivo estudar a sociedade capitalista ocidental a partir da perspectiva histórica dos diversos fatores que influenciaram seu desenvolvimento. Conforme suas palavras:

O capitalismo se nos apresenta em forma diferente nos diversos período da história, porém, a satisfação das necessidades cotidianas, baseada em técnicas capitalistas, só é peculiar no Ocidente; nos países desta região é coisa natural desde a segunda metado do século XIX (WEBER, 1980 p.123).

Ao abordar o capitalismo moderno, Weber destaca que sua existência é condicionada pela "[...] contabilidade racional do capital, como norma para todas as grandes empresas lucrativas que se ocupam da satisfação das necessidades cotidianas" (WEBER, 1980, p.124). E ele desenvolveu e se expandiu por meio da "[...] empresa permanente e racional, da contablidiade racional, da técnica racional e do Direito Racional. A tudo isto se deve ainda adicionar a ideologia racional, a racionalização da vida, a ética racional na economia" (WEBER, 1980, p.169).

Como se pode perceber, na perspectiva de Weber o ponto central para compreender a gênese e a estrutura da sociedade moderna seria a racionalização, "[...] que consistiria na crescente submissão das mais diversas esferas da vida pública e privada à calculabilidade, à impessoalidade e à uniformidade características do formalismo burocrático sob regime de dominação que ele tipificou como racional-legal” (KRAMER, 2000, p.165).

Ainda de acordo com Kramer (2000), a questão central de Weber é

\begin{abstract}
A modelagem de um tipo de humanidade correspondente ao estilo de vida metódico, racional, vocacional que o ascetismo protestante - puritano, calvinista - infundiu no conjunto da cultura moderna e que se manteve, de certo modo, influente, mesmo depois que esta se desprendeu de seu fundamento religioso original (KRAMER, 2000, p. 169).
\end{abstract}

Em suma, o capitalismo se desenvolveu e se expandiu através da empresa, da contabilidade, do Direito racional, mas também a partir de uma ética religiosa racionalizada, ou seja, uma ética baseada não em magia ou misticismo, mas no ascetismo, que "[...] representa a prática de um determinado regime de vida metódico [...]" (WEBER, 1980 p.175) com repercussão em todas as esferas da vida individual e coletiva. Uma vida metódica, com base no ascetismo difundido pela ética calvinista (WEBER, 2004).

Se na esfera individual/privada o racionalismo penetra pela ética calvinista, o domínio racional do Estado se dá pela burocracia, tendo em vista a necessidade de gerir o poder, o 


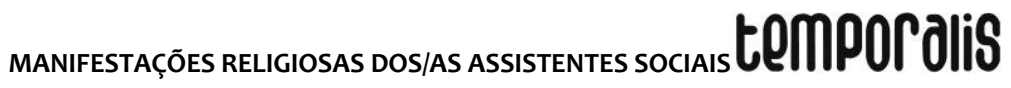

qual se dá por meio de uma organização administrativa especializada, de um direito racional-formal. A burocracia apresenta algumas características que segundo Weber são:

[...] autoridade administrativa circunscrita por leis e regulamentos; hierarquia 'monocrática' com base no princípio da unidade de comando; divisão de trabalho segundo esferas de competência nitidamente demarcadas; universalidade e impessoalidade de procedimentos marcando as relações dos burocratas entre si e com o público em geral; quadros assalariados; recrutamento e promoção de acordo com critérios 'objetivos' de antiquidade e/ ou mérito (exame de provas e títulos) (KRAMER, 2000, p. 171-172).

A burocracia foi, portanto, uma das manifestações do racionalismo - tornando-se questão central no Ocidente, em que o Estado é administrado por regras e funcionários devidamente treinados - e do desencantamento da sociedade, ou seja, o abandono da magia ("desmagificação"), com a ciência tomando cada vez mais consistência e espaço, negando a ideia e a imagem de um mundo religioso. Como destacou Weber (1980, p.178): "A ética econômica nasceu do ideal ascético; todavia, perdeu o sentido religioso".

Entre os problemas econômicos-sociais que ocorrem na sociedade, devem ser estabelecidas distinções: "[...] instituições ou eventos 'econômicos'; fenômenos 'economicamente relevantes'; fenômenos 'economicamente condicionados'" (WEBER, 1986, p. 79). Conforme o autor, não é possível negar o ponto de vista econômico no estudo dos fenômenos sociais, sob prejuízo de se tornar uma ciência geral do social. Mas, também não é possível reduzir para o ponto de vista unicamente econômico estes fenômenos.

Afinal, as estruturas sociais não existem independentes da ação do indivíduo, o qual associa um sentido: "[...] ação social significa uma ação que, quanto a seu sentido visado pelo agente ou os agentes, se refere ao comportamento de outros, orientando-se por este em seu curso" (WEBER, 2004, p. 3).

E é a ação social, isto é, a forma como a pessoa age e se comporta a partir de seus valores, dando sentido à sua ação e estabelecendo relações com as demais pessoas, o que interessa ao sociólogo - compreender o sentido da ação social dada pela pessoa e compartilhada pelos demais. Esse sentido

É o sentido subjetivamente visado a) na realidade $\alpha$, num caso historicamente dado, por um agente, ou $\beta$, em média e aproximadamente, numa quantidade dada de casos, pelos agentes ou b) num tipo puro conceitualmente, construído pelo agente ou pelos agentes concebidos como típicos (WEBER, 2004, p. 4).

Destaca Weber que não é um sentido correto ou verdadeiro, definido pela metafísica, mas de uma ação com sentido visado pelo agente e compartilhada socialmente, cabendo ao sociólogo compreender este sentido que encontra-se na conduta deste agente/pessoa.

O sentido dado pelo agente/pessoa é o motivo e o objetivo da ação; e para o sociólogo, que tem por finalidade compreender a ação do agente/pessoa, "[...] a reconstrução do motivo é fundamental, porque, da sua perspectiva, ele figura como a causa da ação" (WEBER, 1986, p. 27). Ou seja, o sociológo não tem por intenção julgar a validade da ação

Temporalis, Brasília (DF), ano 20, n. 40, p. 182-200, jul./dez. 2020. | ISSN 2238-1856 
e nem compreender o agente, mas cabe compreender o sentido que o agente/pessoa confere à sua ação e seu significado social.

A ação social pode ser caracterizada tendo por base a natureza de sua motivação: "[...] 1. de modo racional referente a fins; 2 . De modo racional referente a valores; 3 . De modo afetivo; 4. De modo tradicional” (WEBER, 2004, p.15). Enfim, ações com motivações racionais ou motivações afetivas ou motivações por costume.

Weber (2004) chama a atenção para o fato de que estas tipologias são modelos conceituais, pois

A ação real sucede, na maioria dos caso, em surda semiconsciência ou inconsciência de seu 'sentido visado'. O agente mais 'sente', de forma indeterminada, do que o sabe ou tem 'clara ideia' dele; na maioria dos casos, age instintiva ou habitualmente. Apenas ocasionalmente e, no caso de ações análogas em massa, muitas vezes só em poucos indivíduos, eleva-se à consciência um sentido (seja racional, seja irracional) da ação (WEBER, 2004, p. 13).

Portanto, o método das ciências da natureza não cabe aos objetivos das ciências sociais, tendo em vista que a realidade social é infinita em suas múltiplas e inesgotáveis diversidades, não sendo possível o estabelecimento de leis - como na Física, na Astronomia ou na Biologia - para entender e determinar a causalidade e a regularidade de um dado fenômeno social. Afinal, o campo das ciências sociais é o da vida sócio-cultural, o "[...] aspecto qualitativo dos fatos sociais" (WEBER, 1986, p.90).

Essa realidade, é complexa, porque as múltiplas relações estabelecidas contêm múltiplas variáveis e conseguências, não seguindo leis previamente estabelecidas. Apenas um fragmento da realidade infinita será de interesse para compreensão do observador, porque ele será “[...] essencial no sentido de 'digno de ser conhecido"” (WEBER, 1986, p.88).

Na verdade, para empreender o estudo da realidade selecionamos apenas um dado fato/evento/situação desta realidade multifacetada e complexa. E esta escolha não se dá de forma aleatória ou ao acaso, porque é condicionada pela subjetividade e pelo ponto de vista do pesquisador. Portanto, deverá o pesquisador saber distinguir "[...] os elementos da realidade a 'valores culturais' universais e destacar aquelas conexões que para nós se revistam de significado" (WEBER, 1986, p.97).

Se o pesquisador seleciona, dentre dezenas de fatos, um deles, na verdade, um fragmento de uma dada realidade, é porque este lhe chamou a atenção, ou por curiosidade científica ou devido a seus valores morais e éticos, com o qual compartilha certos significados culturais comuns.

Para lidar e entender a complexidade da realidade e das relações sociais, são necessários modelos explicativos diferenciados, tendo em vista que "[...] nas condições de sociedades industriais complexas, a situação de classe e o interesse de classe do indivíduo de forma alguma costumam ser claros." (MOMMSEN, 1997, p. 159). 
Para conhecer um dado fenônemo social é necessário entender o sentido, o conteúdo simbólico da ação das pessoas envolvidas neste fenômeno. As leis sociais estabelecem relações causais, ou seja, leis que se referem a construção de comportamento com sentido e servem para explicar processos particulares. Para que seja possível esta explicação, Weber apresenta o tipo ideal, instrumento analítico que relaciona-se a um processo de conceituação que retira de fenômenos concretos o que existe de particular: "Não é uma 'hipótese', mas pretende apontar o caminho para a formação de hipóteses. Embora não constitua uma exposição da realidade, pretende conferir a ela meios expressivos unívocos" (WEBER, 1986, p. 106). Expondo de forma simples, são modelos conceituais para explicar uma dada fração da realidade social.

Conforme Weber (1986), tipos ideais são meios ou formulações hipotéticas - conceitos para apreender os indivíduos históricos, já que "[...] trata-se de um quadro de pensamento, e não da realidade histórica, e muito menos da realidade 'autêntica"” (WEBER, 1986, p. 109). A realidade social é infinita e complexa, e os tipos ideais são modelos que possibilitam compreender esta multiplicidade.

E para compreender e desvelar essa realidade, Weber ressalta a necessidade da objetividade, por meio de pressupostos que garantem a neutralidade valorativa, ou seja, a importância de o pesquisador manter um distanciamento em relação à realidade que constitui seu objeto de estudo:

Weber formula a exigência de que o recurso à compreensão se dê mediante um 'distanciamento' do pesquisador em relação ao seu objeto e nunca através de algum procedimento de identificação empática com o agente em questão (TRAGTENBERG, 1980, p. 28).

Os valores do pesquisador aparecem no momento em que este delimita, a partir de seu ponto de vista e em meio à complexidade e multiplicidade da sociedade e suas relações, o que será investigado. São seus valores que selecionam o que é importante a ser estudado e a formação do sistema conceitual utilizado. Contudo, Raquel Weiss (2014), resumindo o argumento de Weber, escreve que "[...] as Ciências Sociais não podem se pronunciar sobre a validade normativa (Geltung), mas apenas podem discutir sua vigência empírica (Gültigkeit) e assim lançar luz sobre as condições e as consequências da realização dos valores" (WEISS, 2014, p. 115).

O pesquisador poderá discordar no que se refere a forma de analisar determinado fato da realidade social; mas, definido o que estudar, deverá fazê-lo de modo sistemático e objetivo, adotando um método de análise que não deixe, ou não deveria deixar, dúvidas quanto ao percurso metodológico a ser seguido. Enfim, é importante para o êxito da atividade cientítica, a abstenção das ideias e do juízo de valor no âmbito do exercício acadêmico. Deverá o pesquisador ser investigador e não proselitista durante sua atividade acadêmica.

Com base nesta enunciação, também a ação profissional do assistente social deve estar ancorada no conhecimento científico adquirido e desenvolvido no processo de formação, visando superar o senso comum, ou melhor, o voluntarismo e o fazer espontâneo. 
Nas Diretrizes Gerais para o Curso de Serviço Social, o item dois dos princípios que fundamentam a formação profissional destaca: "Rigoroso trato teórico, histórico e metodológico da realidade social e do Serviço Social, que possibilite a compreensão dos problemas e desafios com os quais o profissional se defronta no universo da produção; e reprodução da vida social [...]" (ABEPSS, 1996, p.6); e o Código de Ética, no item X dos Princípios Fundamentais salienta o "Compromisso com a qualidade dos serviços prestados à população e com o aprimoramento intelectual, na perspectiva da competência profissional" (BRASIL, 2012, p. 24).

Isto posto, surgiu o interesse de investigar e explicar as motivações e as conseguências da influência de princípios religiosos durante a atividade profissional do assistente social, respaldando, para construção do arcabouço teórico - metodológico, na ideia de ação social e sentido da ação. Os interesses econômicos por vezes não são os únicos determinantes no agir social de certos grupos, tendo em vista que a ação de homens e mulheres é influenciada por uma diversidade de fatores, como crenças religiosas, comportamentos e valores de seu grupo social (MOMMSEN, 1997, p.159).

\section{AÇÃO E SENTIDO DA RELIGIÃO NA PRÁTICA PROFISSIONAL DO ASSISTENTE SOCIAL}

De acordo com o Novo Mapa das Religiões, publicação da CPS/FGV (NÉRI, 2011), o Catolicismo vem sofrendo uma queda significativa de membros ao longo dos anos, enquanto que as igrejas pentecostais e neopentecostais seguem uma forte tendência de crescimento, fato que tem levado à revalorização de aspectos sagrados e religiosos na sociedade brasileira, estendendo-se por todas as esferas da vida individual, social, política e econômica ${ }^{2}$. Centenas de templos religiosos ficam lotados de fiéis e é incontável o número de seitas e denominações religiosas, além da retomada de dogmas e doutrinas religiosas para orientar comportamentos e normas sociais e determinar concepções de homem e de mundo (MORI; SILVA, 2016). Seria o retorno ao "reencantamento do mundo"?

Fenômeno social que tem provocado estranheza em algumas áreas acadêmicas - Serviço Social, por exemplo - mas que já vem sendo investigado por sociólogos e historiadores do campo das religiões há algum tempo, os quais buscam compreender as motivações para o crescimento da presença de valores e princípios religiosos na contemporaneidade e as repercussões nas instâncias econômica, política, social e cultural ${ }^{3}$. Entre estas repercussões, interessou-nos verificar como se dá o processo de (re)valorização de aspectos religiosos entre os profissionais do Serviço Social e sua presença durante o exercício profissional em Londrina e em algumas cidades da região norte do Paraná. Afinal, já na década de 1980 a teoria social crítica haiva conquistado a hegemonia no campo acadêmico do Serviço Social, com o objetivo de superar uma prática profissional fundamentada em ideias e atitudes conservadoras - como a execução de tarefas que visavam adequar as pessoas à ordem social estabelecida, apoiada em expressões moralizantes e moralizadoras - e também com o objetivo de garantir o direito de acesso dos trabalhadores às políticas sociais, a defesa dos direitos humanos e de um Estado laico.

\footnotetext{
${ }^{2}$ Para maior aprofundamento a respeito da história do movimento pentecostal, ler: Campos (1996, p.77118); Freston (1996. p. 67-159) e Sanchis (1996, p. 34-63).

${ }^{3}$ Para se aprofundar nesta temática sugerimos: Brandão (2004), Carvalho (1998), Mendonça (1995) e Montes (1998, p. 63-171).
}

Temporalis, Brasília (DF), ano 20, n. 40, p. 182-200, jul./dez. 2020. | ISSN 2238-1856 
Iniciamos a pesquisa com os assistentes sociais no ano de 2013 para verificar a presença e a influência de princípios e valores religiosos na prática profissional. Utilizamos como instrumento de coleta de dados questionários (fechados) e entrevistas (com roteiro semiestruturado), os quais foram aplicados junto aos profissionais que atuam na implementação de políticas sociais: assistência social, saúde, habitação, educação, área organizacional. Os locais de coleta de dados foram no I Seminário Nacional: gestão de políticas sociais e território (abril de 2013), promovido pelo Núcleo de Estudos e Pesquisa sobre Gestão de Políticas Sociais e nas instituições socioassistenciais onde os profissionais atuam.

Foram aplicados 147 questionários aos assistentes sociais da cidade de Londrina e de vários municípios da região norte e noroeste do Paraná. Destes, 96 questionários foram respondidos e analisados na primeira etapa da pesquisa. Nestas análises, verificamos que ainda há jovens e adultos que ingressam no curso motivados pela perspectiva da ajuda e da caridade, além de muitos profissionais valorizarem aspectos religiosos em sua atuação profissional.

Por último, destacamos a incipiente problematização - dentro e fora dos espaços acadêmicos - quanto a influência de valores e princípios religiosos nos indivíduos e nas esferas social, política, cultural e econômica e que repercutem na formação profissional (Retirado para não identificar o autor).

Foi a partir destas considerações que continuamos a investigação, com a aplicação de mais 29 questionários - totalizando 125 questionários - e a realização de entrevistas com 11 (onze) assistentes sociais para possibilitar maior aproximação com o objetivo proposto, ou seja, como o profissional vive sua religiosidade no cotidiano. A coleta de dados foi nos dias de aulas de cursos de Pós-Graduação latu sensu ocorridos em faculdades localizadas em cidades próximas a Londrina e nos locais de trabalho dos profissionais que aceitavam participar da pesquisa.

Antes de continuarmos, quando nos referimos a religiosidade queremos dizer que é a expressão pessoal de fé que ultrapassa a dimensão corporal e dá sentido à vida do indivíduo, determinando, na maioria das vezes, o seu comportamento e suas ações. Consideramos que a religiosidade não está apenas vinculada a uma igreja ou denominação, cada pessoa a constrói a partir de sua história de vida, ou seja, de sua condição de vida material e subjetiva (SILVA, 2008).

Nesta mesma linha de raciocínio, entendemos que os valores e princípios religiosos são construções e elaborações individuais estreitamente vinculados à história de cada pessoa, as quais por sua vez, são influenciadas pelo modo de produção e organização de uma dada sociedade. Enfim, os valores e princípios não se constituem de forma isolada, mas encontram-se vinculados ao processo histórico social global.

As religiões e suas instituições usualmente organizam e dão sentido (direção) à religiosidade e reforçam os princípios e valores de seus membros, conforme suas normas e doutrinas, garantindo desta forma, a reprodução de suas ideias religiosas e sua continuidade enquanto instituição. 
Como Weber evidenciou, na qualificação profissional dos líderes religiosos lhes são ensinados saberes próprios de uma doutrina e uma ética religiosa, as quais, por sua vez, serão transmitidas nas celebrações religiosas e utilizadas para regular a vida de cada um dos fiéis (SILVA, 2008).

Com a tipificação de religiosidade iniciamos a análise para compreender este fenômeno entre os assistentes sociais, assim como a presença e a influência de princípios e valores religiosos durante a atividade profissional, isto é, como estes dão sentido à sua ação sentido subjetivamente visado pelo agente/assistente social - e que se revela em ações concretas (COHN, 1986).

Dos 125 questionários respondidos, 86.4\% profissionais declararam que frequentam um espaço religioso:

Tabela 1: Igreja que frequenta

\begin{tabular}{|l|l|l|l|l|l|}
\hline Igreja & Católica & Evangélicas & Espíritas & Candomblé & Não respondeu \\
\hline Profissionais & $64.8 \%$ & $21.3 \%$ & $5.5 \%$ & $0.9 \%$ & $1.8 \%$ \\
\hline
\end{tabular}

Fonte: Questionário aplicado aos assistentes sociais.

Dados que não diferem do que foi apontado pelo censo de 2010, isto é, a maioria da população declara-se da Igreja Católica, vindo a seguir as igrejas evangélicas - de diferentes denominações (IBGE, 2010).

É significativa a presença e a participação nestes espaços: dos 108 profissionais que responderam, $71.3 \%$ afirmaram frequentar de forma assídua - uma vez por semana ou mais de duas vezes. Cabe destacar que 70 (setenta) afirmaram que sempre frequentaram a denominação religiosa, ou seja, não mudaram de igreja.

Este dado pode significar que houve pouco trânsito religioso entre os profissionais que responderam ao questionário, característica que tem sido registrada entre os jovens nos últimos anos e estudada por sociólogos da religião, como Danièle Hervieu-Léger (2008, p. 80): "A religiosidade das sociedades modernas está em movimento: é este movimento que se precisa conseguir identificar". Mas, o fato de o assistente social não mudar de religião não quer dizer que não houve alterações em sua religiosidade.

Essas mudanças, a partir de nossos dados - os quais serão explorados mais adiante trazem uma expressiva influência da teologia pentecostal, cuja base é o fervor religioso e a leitura literal da bíblia. Essa teologia hoje está presente em todas as igrejas, incluindo as igrejas históricas tradicionais (Católica, Luterana, Anglicana, Presbiteriana, Metodista); afinal todas as denominações religiosas estão em busca de membros - sem "clientes" não há como sobreviver em um mercado extremamente competitivo. Desde a década de 1970 cresce o número de igrejas pentecostais e neopentecostais, e para ter sucesso no competitivo mercado religioso é fundamental adequar-se aos interesses e anseios de seu público.

Uma igreja que ofereça respostas ou consolo para as situações que seus membros estão vivendo, que promete uma vida tranquila e estável para quem seguir as determinações de seus líderes. São igrejas que incentivam uma religiosidade baseada na emoção e nas 


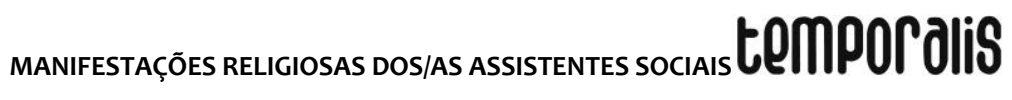

necessidades e vontades pessoais, e cujo deus atenderá aos que demonstrarem devoção e dedicação.

Para as igrejas que se fundamentam na teologia pentecostal, o mal (diabo, demônio, capeta) é uma realidade concreta que se manifesta no cotidiano das pessoas - a falta de emprego, as doenças (físicas e mentais), a violência doméstica, o vício. Situações que provocam o caos e a desordem na vida pessoal e na coletividade, havendo a necessidade de dedicação, vigília, oração e jejum (SILVA, 2008).

Portanto, há pouca diferença na teologia e doutrina das igrejas evangélicas, o que significa que mudar de igreja não necessariamente ocorrerão mudanças na concepção de mundo e normas reguladoras de comportamento. Ademais, até mesmo os líderes religiosos das igrejas históricas tradicionais também realizam suas celebrações a partir das premissas da teologia pentecostal.

Essa teologia, não obstante a perspectiva mágica-religiosa, não se contrapõe ao que Weber destacou, porque além de não propagar a fuga do mundo profano, fundamenta-se em uma ética racional da vida diária, ou seja, o autocontrole da vontade, dos desejos e da conduta e dedicação aos preceitos da igreja.

Quanto a motivação para participar, $68.5 \%$ profissionais declararam que se dá em razão de tradição familiar, ou seja, herança dos pais e $16.6 \%$ informaram que se deu por motivo de conversão. E ao indagar se a vida mudou após a participação na igreja, $75 \%$ dos assistentes sociais informaram que sim.

Estes números demostram que não há a necessidade de converter-se a outra igreja para que haja mudanças na vida, considerando que uma situação extrema - doença, morte, divórcio - pode levar a pessoa a rever sua concepção de mundo e levar à busca de novas experiências, produzindo mudanças em suas condições subjetivas, em sua individualidade, porque cada indivíduo possui seus desejos, vontades, necessidades, as quais estão intimamente ligadas a um determinado tempo histórico. Como destacou Weber (2004, p. 279), a ação religiosa ou "magicamente motivada" é uma ação racional, orienta-se pelas regras e normas da experiência.

Há ainda situações como o medo do desemprego, a precariedade do trabalho, a competitividade que desafia a solidariedade, o pouco reconhecimento social, as quais levam a situações de sofrimento e a perspectiva de um futuro incerto. São questões pessoais que acabam por provocar mudanças também nas organizações religiosas.

Outro dado que nos chamou a atenção foi o fato de que $93.5 \%$ declararam que o vínculo religioso já ajudou em algum momento de sua vida. Afinal, a vida cotidiana e seus variados conflitos exigem múltiplas respostas.

Se não é possível entender homens e mulheres fora de suas condições objetivas e subjetivas de existência e da atividade coletiva - econômicas, sociais, políticas, culturais também não se pode menosprezar que o movimento individual gera mudanças na sociedade, situação que Weber chamou a atenção quando de seu estudo sobre religiões: “'A ação ou pensamento religioso ou 'mágico' não pode ser apartado, portanto, do círculo

Temporalis, Brasília (DF), ano 20, n. 40, p. 182-200, jul./dez. 2020. | ISSN 2238-1856 
das ações cotidianas ligadas a um fim, uma vez que também seus próprios fins são, em sua grande maioria, de natureza econômica" (WEBER, 2004, p. 279).

Neste caso em particular, ou seja, o crescimento das manifestações religiosas, já destacamos que uma das possíveis causas é o momento histórico pelo qual passamos, em que os valores e princípios são constituídos considerando os valores dominantes consumismo, hedonismo, individualismo - que definem e ordenam as relações sociais, políticas e econômicas (SILVA; TERUEL; SILVA, 2017).

Há uma interação entre as questões objetivas, materiais, que determinam as condições de existência, com as questões de cada pessoa, que condiciona e desafia sua subjetividade e desconstrói e reconstrói sua identidade.

Todos os profissionais declararam que vivem sua espiritualidade diaramente, por meio de orações, jejuns e $53.7 \%$ informaram que relacionam aspectos do trabalho com as questões religiosas ou à sua religiosidade. São números que nos levam a inferir que as questões trazidas pelos usuários das políticas sociais por vezes são entendidas a partir de uma perspectiva religiosa. Algumas falas reforçam nossa afirmação:

[...] como cristã creio firmemente que as pessoas devem buscar viver uma vida de mais contemplação e menos consumo, mais solidariedade, que individualismo, em comunhão com o criador, na tentativa de unir e agregar mais e combater todas as formas de violência e intolerância. (AS1)

$\mathrm{Sim}$, tento bastante, relacionar o que eu aprendo na igreja, o que eu vivo na igreja também no meu trabalho pra não ter aquela dicotomia eu ter uma teoria e uma prática diferenciada. (AS2)

Eu relaciono porque na verdade eu acredito muito na bíblia e a bíblia tem muitas passagens que diz que com o passar do tempo as coisas iriam ficando piores e eu acredito que muitos problemas sociais é de acordo com o que está escrito na bíblia. (AS3)

Os problemas sociais são entendidos enquanto situações provocadas por razões que estão fora do mundo profano e, portanto, as respostas deverão estar no plano sagrado. Fato que nos leva a afirmar que a sociedade brasileira não é secularizada, arriscaríamos escrever, nunca fomos uma sociedade secularizada, situação em que o Estado é pautado no direito racional e em uma burocracia especializada e profissional, contando com funcionários qualificados e admitidos conforme sua competência.

Portanto, o que verificamos é que se os profissionais do Serviço Social que atuam na implementação das políticas sociais - geralmente admitidas por meio de concurso público ou por indicação - por vezes têm sua ação pautada em princípios que podem gerar situações que provoquem impasses e divergências entre o profissional e o usuário, destoando do que está preconizado no Código de Ética: "Exercício do Serviço Social sem ser discriminado/a, nem discriminar, por questões de inserção de classe social, gênero, etnia, religião, nacionalidade, orientação sexual, identidade de gênero, idade e condição física" (BRASIL, 2012, p. 25).

Ações profissionais cujo sentido estão fundamentados em valores e princípios religiosos, nos exige reatualizar o debate sobre o significado e a importância da laicidade - a

Temporalis, Brasília (DF), ano 20, n. 40, p. 182-200, jul./dez. 2020. | ISSN 2238-1856 


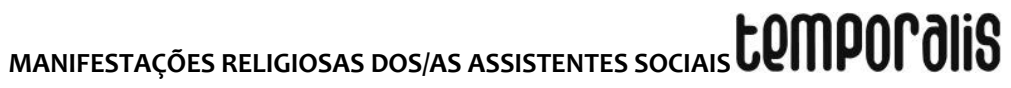

separação entre Estado e Igreja, entre esfera civil e religiosa - para o profissional do Serviço Social, como já destacado em publicação anterior (SILVA; DUTRA; LANZA, 2016).

Professar uma religião, ser membro ativo de uma denominação religiosa é uma questão individual e particular, garantido e protegido pela Constituição brasileira. Porém, durante a atividade profissional, o que deve prevalecer são os princípios e os direitos dos usuários das políticas sociais consubstanciados em leis.

Por outro lado, na fala de alguns profissionais verificamos a preocupação em delimitar seus princípios e a atuação profissional:

Tem que deixar claro a atuação profissional, nos momentos em que você está atuando profissionalmente tem que ser amparado pelo seu código de ética, pelo projeto ético político, eu sempre me norteio pelos documentos que legitimam a profissão. (AS 4)

O profissional do Serviço Social lida com situações adversas, convocado a dar respostas que as instituições empregadoras, usualmente públicas, não têm condições de atender. Neste sentido, a busca para solucionar ou atenuar o problema que se apresenta vai na direção do que o profissional já conhece desde sempre, ou seja, a religião. Como já havíamos destacado anteriormente, o assistente social tem o interesse de conciliar sua ação com os interesses dos usuários das políticas públicas, contudo, também tem que lidar com suas dificuldades, conflitos e medos que experimenta em seus relacionamentos pessoais (SILVA; DUTRA; LANZA, 2016).

As condições subjetivas não podem ser subestimadas, sob risco de não compreendermos a atividade profissional do assistente social em sua totalidade, porque, conforme Sônia Mansano (2010), é exigido do profissional conhecer as legislações sociais e os procedimentos legais, além de estar em contato direto com os problemas que afligem a população que atende, em condições difíceis e fora de possibilidade de amparo.

Se nos voltarmos para Weber, observaremos que suas análises sobre a sociedade havia uma preocupação em demonstrar que

[...] as pessoas nem sempre agem de acordo com sua situação classista objetiva; suas ações são influenciadas por uma multiplicidade de outros fatores, entre os quais se incluem principalmente convicções religiosas, modos tradicionalistas de comportamento ou, ainda, posturas específicas de valor (MOMMSEN, 1997, p.159)

Se por um lado não podemos nos limitar à particularidade individual, por outro lado, devemos considerar que o sucateamento das políticas sociais reverberam no exercício profissional e, consequentemente, na esfera emocional dos profissionais, porque são eles que lidam diretamente com os usuários e seus problemas. Nos relatos dos assistentes sociais, alguns apontaram a dificuldade para conciliar os problemas enfrentados em sua vida particular com as questões cotidianas do trabalho:

Você procura se dedicar em tudo aquilo que você faz. Busca orientar as pessoas da melhor forma porque, a palavra de Deus fala, não digo amar teu próximo como a ti mesmo, que eu quero ver se alguém ama o próximo como a si mesmo no dia a dia. Porque até conflito familiar a gente tem, com os filhos, com o

Temporalis, Brasília (DF), ano 20, n. 40, p. 182-200, jul./dez. 2020. | ISSN 2238-1856 
marido. Que a gente está sempre na correria, sempre cheia de coisas pra fazer e as horas vão passando e a gente tem os compromissos, as cobranças tanto no trabalho como em casa. Não tem como você desconsiderar tudo isso no momento em que você vai na casa da pessoa. A pessoa está lá deitada, faz dois anos que está lá desempregada. Você oferece curso, não vai. Você fala pra fazer cadastro único, não vai, mas na hora de ir lá pra reunião da cesta básica vai.

(AS 5)

Além disso, o assistente social é um trabalhador assalariado inserido na divisão social e técnica do trabalho; desta forma, também é atingido pela precarização do trabalho, pelos baixos salários, pela degradação da vida social, pelo racismo, pela violência de gênero. Enfim, por vezes vivendo situações próximas aos usuários que atende.

Isto posto, devemos ter em mente que os profissionais levam para a ação cotidiana suas características e particularidades pessoais, constituídas nas relações que estabelecem em seus grupos sociais - origem de classe, gênero, raça, etnia, formação escolar e religiosa e que interfere em seu exercício profissional. Se o assistente social participa assiduamente de manifestações religiosas e concebe o mundo a partir de valores e princípios religiosos, no momento de sua atividade profissional também fará uma leitura da realidade que lhe é apresentada a partir da perspectiva religiosa. Fato que verificamos no depoimento de assistentes sociais:

As situações que as pessoas me apresentam, as pessoas que eu atendo eu relaciono sim com a reencarnação porque a gente fica pensando, porque tem pessoa que é rica saudável glamorosa e tem outras pessoas que passam por situações tão difíceis e a explicação religiosa que eu tenho é a reencarnação. (AS 6)

Eu me baseio muito em como avaliar situações em cima da minha formação, não só da minha formação técnica, mas também na minha formação espiritual, religiosa. Eu percebo assim que existem as visões de mundo, as visões de pessoas que diferem muito quando um profissional ele tem alguma formação religiosa diferente da minha. (AS 7)

Homens e mulheres são imprevisíveis, volúveis e contraditórios, moldados a partir de suas condições materiais e de suas experiências na infância, na juventude e na vida adulta, que os provocaram a construírem, desconstruírem e reconstruírem concepções de homem e mundo. $E$ as experiências vividas nestes processos serão levadas para diferentes campos onde estes indivíduos estabelecerão relações.

Se suas concepções se fundamentam considerando a experiência religiosa e a religiosidade, entenderão o mundo a partir desta perspectiva, acreditando que a religião Ihes forneça respostas de como enfrentar as constantes dificuldades materiais, pessoais e profissionais. Se a busca para enfrentar os dissabores cotidianos se dá no plano espiritual porque depende da fé em um deus poderoso e onipotente, os motivos para existirem homens e mulheres em situação de extrema pobreza estariam em uma esfera interna que somente cada indivíduo poderia superar; indo ao encontro do que Weber apontou em seu texto:

A contravenção da vontade do deus é agora um 'pecado' ético que pesa sobre a consciência, independentemente das consequências imediatas. Males que atingem o indivíduo são calamidades que o deus mandou e consequências do pecado, das quais o indivíduo espera poder livrar-se, encontrando 'salvação',

Temporalis, Brasília (DF), ano 20, n. 40, p. 182-200, jul./dez. 2020. | ISSN 2238-1856 


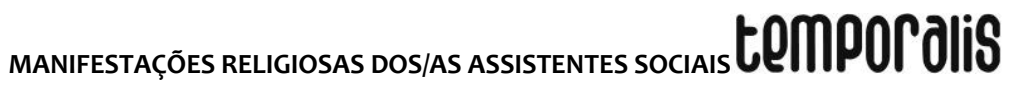

mediante um comportamento que agrada ao deus - a 'piedade' (WEBER, 2004, p. 302).

A formação profissional do assistente social fundamenta-se em bases teóricas críticas (ao menos como preconiza as Diretrizes Curriculares) e metodológicas; contudo, no enfrentamento diário com as questões trazidas pelos usuários das políticas públicas, por vezes estas bases são suplantadas pelas convicções religiosas:

Não deveria interferir, mas como somos seres humanos, carregamos uma história de vida e também nossos valores, muitos deles estão arraigados, que vez por outra durante nossas intervenções, acabamos por agir de uma forma que vai de encontro com o que eu creio. Ela acontece sutilmente, e deveria ser evitada, mas muitas decisões, são feitas a partir das minhas convicções (AS 1)

É importante entender que a reatualização e o fortalecimento do conservadorismo, particularmente o conservadorismo religioso, na prática profissional está vinculado a um processo maior que abrange os campos econômico, político, social, cultural e religioso. $\mathrm{O}$ fortalecimento da perspectiva neoliberal - em que o mercado é o espaço legítimo para resolução dos problemas, assim como para regulação das relações sociais - e a subordinação dos interesses e necessidades sociais às estratégias mercantis, são medidas que levam ao fortalecimento da competitividade, do individualismo e dos valores liberais conservadores (SILVA, 2006).

Como frisou Weber logo no início de seu texto Sociologia da Religião "A ação religiosa ou magicamente motivada, em sua existência primordial, está orientada para este mundo" (WEBER, 2004, p. 279). Ou seja, a religião, a religiosidade, os valores e princípios religiosos deverão dar sentido e sustentação às ações individuais e coletivas. Assim sendo, o crescimento deste fenômeno está em plena conformidade com o que observamos cotidianamente nas falas dos profissionais, nos discursos de líderes religiosos e políticos.

Com o aperfeiçoamento tecnológico, possibilitando a geração de novos produtos e a fabricação em massa, estimulando o consumismo e a satisfação imediata, as relações interpessoais também tornam-se provisórias, imediatas, e com ela, as normas e regras que regem tais relações. Se essas relações são forjadas tendo em vista os interesses individuais imediatos, os valores e as normas de convivência também serão imediatas e provisórias, visando preferencialmente os interesses e prazeres de cada indivíduo em particular (BAUMAN, 2001).

Como já consideramos em textos anteriores, diante da flexibilidade e da provisoriedade das mercadorias e das relações sociais, homens e mulheres estão em busca de relações pessoais fundadas no afeto, na satisfação e no prazer, tendo a liberdade individual e a liberdade de escolha como essenciais para a conquista da felicidade no plano terreno, assim como ressalta-se a importância de viver o presente, não cabendo a necessidade de dedicação e filiação a uma luta ou causa, seja ela social, política ou ambiental, porque não estaria diretamente ligada ao cotidiano e os resultados se dariam a longo prazo (SILVA; LANZA, 2012).

Por conseguinte, a religião torna-se o "porto seguro", porque proporciona consolo perante uma sociedade hedonista e respostas às situações inexplicáveis: 
Tenho visto muitas pessoas, adoecidas, sem paz, sem objetivos, presas em muitos vícios, buscando sempre buscando ... muitas delas caindo em depressão emocional, ou na doença mesmo, e talvez neste momento do dor e profunda solidão estejam se rendendo a Deus, através da igreja, cultos e celebrações. (AS 1)

... Afinal em cada esquina tem uma igreja, é um momento em que a própria humanidade tem buscado no que se agarrar, em movimento é uma busca por alternativas e soluções. (AS 4)

Pra mim, eu acho que o desenvolvimento da espiritualidade é muito importante, é fundamental. Não de uma religião em si, mas o desenvolvimento de uma espiritualidade pra qualquer pessoa. Dá muito mais equilíbrio, muito mais base, uma estrutura para que a pessoas possa se desenvolver, eu acho essencial a pessoa ter um desenvolvimento espiritual. (AS 7)

[... ] as pessoas quando vêm para o tratamento, elas buscam outras vertentes de apoio e é muito comum eles procurarem uma igreja. E é muito comum eles falarem que começaram a frequentar uma igreja e que estão mais fortalecidos. $E$ essa questão do usuário de álcool e drogas, ela é bem comum escutar esse tipo de fala de eles terem ido procurar algum apoio religioso e a maioria deles hoje vão par a igreja evangélica porque lá eu acho que acaba sendo um pouco mais acolhedora. Tendo uma doutrina de não poder fazer algumas coisas em relação a vida mundana, e isso para o paciente, é como se fosse uma coisa mais dura que ajuda a colocar eles na linha e mantê-los longe daquilo que é prejudicial pra eles, e é bem comum eles procurarem. (AS 8)

Nesse sentido, o que testemunhamos é a revalorização de elementos religiosos, ou como destaca alguns Sociólogos das Religiões ${ }^{4}$, verifica-se um reencantamento do mundo, ou melhor dizendo, uma magificação do mundo. Conquanto a modernidade tenha trazido a racionalidade das relações econômicas e sociais, o ascetismo, ou seja, uma prática de vida metódica, a "[...] ideologia racional, a racionalização da vida, a ética racional na economia” (WEBER, 1980, p.169), além do desenvolvimento tecnológico, as ideias e os valores religiosos estão perpassando todos os setores da sociedade brasileira - basta observarmos a eleição do capitão da reserva Jair Messias Bolsonaro para a Presidência da República, cuja campanha baseou-se no discurso da moral religiosa e dos bons costumes, além do amplo apoio de líderes religiosos - católicos e evangélicos.

O discurso de vitória do presidente eleito iniciou-se com uma oração de um de seus apoiadores de campanha, asseverando este reencantamento do mundo a que nos referimos - https://www.youtube.com/watch?v=iwD81eWSQNA.

Fica-nos uma indagação, os assistentes sociais podem ficar imunes a este reflorescimento e fortalecimento das ideias religiosas? É necessário, e urgente, discutirmos e tratarmos este tema nas universidades, nas salas de aulas, nos locais de trabalho, visando garantir o que está disposto na Constituição em seu Artigo $5^{\circ}$ : “Todos são iguais perante a lei, sem distinção de qualquer natureza, garantindo-se aos brasileiros e aos estrangeiros residentes no País a inviolabilidade do direito à vida, à liberdade, à igualdade, à segurança e à propriedade" (BRASIL, 1988).

\footnotetext{
${ }^{4}$ WILLAIME, J-P. Sociologia das Religiões. São Paulo: Ed. UNESP, 2012. GOUVEIA, E.H.; JARDILINO, J.R.L.; SOUZA, B.M. Sociologia da Religião no Brasil. São Paulo: PUC/SP, UMESP, 1996.
}

Temporalis, Brasília (DF), ano 20, n. 40, p. 182-200, jul./dez. 2020. | ISSN 2238-1856 


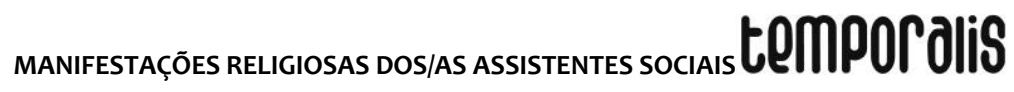

Assim como também estabelecido nos Princípios Fundamentais do Código de Ética: "Empenho na eliminação de todas as formas de preconceito incentivando o respeito à diversidade, à paticipação de grupos socialmente discriminados e à discussão das diferenças".

\section{CONSIDERAÇÕES FINAIS}

Ao nos propormos investigar religião e religiosidade do assistente social e entender a presença de valores e princípios religiosos em suas ações profissionais - e as possíveis determinações e causas destes valores, consideramos que não é possível entender a reatualização do pensamento conservador (no espaço deste artigo, o pensamento conservador religioso), que reativou políticas e ações conservadoras, fora do cotidiano da atividade profissional. E para materializar o objetivo, construímos nosso arcabouço teórico e metodológico a partir de Max Weber, teórico clássico que se propôs, entre outros objetivos, analisar as ações sociais - e seus sentidos - e compartilhadas socialmente, assim como suas determinações.

A partir da pesquisa que realizamos, podemos considerar que o profissional tem evocado o pensamento religioso, tanto em sua conduta pessoal como profissional, para compreender as questões à sua volta. Pensamento e perspectiva religiosa que se verifica em diversas esferas da sociedade e que interpenetram no cotidiano profissional.

A atuação na defesa dos direitos sociais por vezes esbarra nas ideias religiosas, já que a religião tem por intenção apresentar explicações para problemas e questões pessoais, sociais, econômicas, políticas a partir de causas que estão fora do plano terreno, legitimando desta forma, o que está estabelecido e ordenado na sociedade.

Por isso a atualidade e pertinência dos escritos de Weber (2004) sobre religião, quando este destaca que a derrota perante o inimigo não é em virtude da falta de poder do deus local, mas é em decorrência das infrações dos adeptos das ordens religiosas protegidas por este deus. Pecados que provocam a ira de deus, que castiga e educa seu povo/adeptos.

Um tema instigante que a realidade está a exigir estudos para entender as consequências do fundamentalismo religioso na sociedade brasileira contemporânea e particularmente entre os profissionais do Serviço Social.

\section{REFERÊNCIAS}

ABEPSS. Diretrizes gerais para o curso de Serviço Social (Com base no currículo mínimo aprovado em Assembleia Geral Extraordinária de 8 de novembro de 1996). UERJ: Rio de Janeiro, 1996. Disponível em:

http://www.abepss.org.br/arquivos/textos/documento_201603311138166377210.pdf. Acesso em: 4 nov. 2018.

BAUMAN, Z. Modernidade líquida. Rio de Janeiro: Zahar, 2001. 
BRANDÃO, C. R. Fronteira da fé - Alguns sistemas de sentido, crenças e religiões no Brasil de hoje. Estudos Avançados, São Paulo, v.18, n. 52, set./dez. 2004.

BRASIL. Código de Ética do Assistente Social. Lei 8662/93 de regulamentação da profissão. 10. ed. ver. atual. Brasília: CFESS, 2012. Disponível em: http://www.cfess.org.br/arquivos/CEP_CFESS-SITE.pdf. Acesso em: 4 nov. 2018.

BRASIL. Constituição da República Federativa do Brasil. Brasília (DF), 1988. Disponível em: http://www.planalto.gov.br/ccivil_03/Constituicao/Constituicao.htm. Acesso em: 1 nov. 2018.

CAMPOS, L. S. Protestantismo histórico e pentecostalismo no Brasil: aproximações e conflitos. In: NA FORÇA do espírito: os pentecostais na América Latina: um desafio às igrejas históricas. São Paulo: AIPPRAL, 1996. p.77-118.

CARVALHO, J. J. Religião, Mídia e os Predicamentos de uma Existência Pluralista. Sociedade Global, Cultura e Religião.Petrópolis: Vozes, 1998.

COHN, G. Weber. 3. ed. São Paulo: Ed. Ática, 1986. p. 7-34

FRESTON, P. Breve história do pentecostalismo brasileiro. In: Antoniazzi, Alberto et al. Nem anjos nem demônios: interpretações sociológicas do pentecostalismo. 2. ed. Petrópolis: Vozes, 1996. p. 67-159.

HERVIEU-LÉGER, D. O peregrino e o convertido: a religião em movimento. Petrópolis/RJ: Ed. Vozes, 2008.

KRAMER, P. Alexis de Tocqueville e Max Weber: respostas políticas ao individualismo e ao desencamento da sociedade moderna. A Atualidade de Max Weber. Brasília (DF): Ed. Universidade de Brasília, 2000. p. 163-196.

MANSANO, S.V. Dimensões afetivas atualizadas no trabalho do Assistente Social. Serviço Social em Revista. Londrina, v. 12, n.2, p. 33-49, jan./jun. 2010. Disponível em: http://www.uel.br/revistas/uel/index.php/ssrevista/article/view/7541/6832. Acesso em: 6 e 15 nov. 2018.

MENDONÇA, A. G. O celeste porvir: a inserção do protestantismo no Brasil. São Paulo: ASTE, 1995.

MOMMSEN, W. Capitalismo e socialismo. O confronto com Karl Marx. In: GERTZ, René E. (org.). Max Weber \& Karl Marx. 2. ed. São Paulo: HUCITEC, 1997. p. 146-178

MONTES, M.L. As figuras do sagrado: entre o público e o privado. História da Vida Privada, v. 4. São Paulo: Cia das Letras, 1998. p. 63-171.

MORI, V.T.; SILVA, C.N. A religiosidade dos estudantes de uma universidade pública: considerações a partir do curso de Serviço Social. PLURA, Revista de Estudos de Religião, v. 7, n. 1, p. 439-457, 2016. Disponível em: http://www.abhr.org.br/plura/ojs/index.php/plura/article/viewFile/1131/pdf_171. 


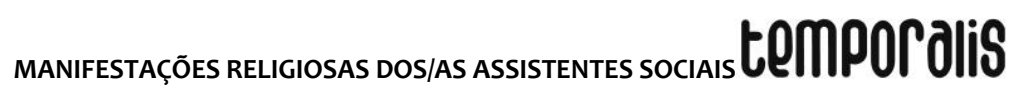

NÉRI, M. (Coord.). Novo Mapa das Religiões. CPS/FGV: Rio de Janeiro, 2011.

SANCHIS, P. O repto pentecostal à cultura católico-brasileira. In: Antoniazzi, Alberto et al. Nem anjos nem demônios: interpretações sociológicas do pentecostalismo. 2. ed. Petrópolis: Vozes, 1996. p. 34-63.

SILVA, C.N. As ações assistenciais promovidas pelas igrejas pentecostais no Município de Londrina (1970 - 1990). 181 p. Assis. Tese (Doutorado em História Social) - Faculdade de História, Universidade Estadual Paulista, 2008.

SILVA, C.N. Igreja Católica, assistência social e caridade: aproximações e divergências. Sociologias, Porto Alegre, n.15, p. 326-351, jan/jun 2006. Disponível em: http://www.scielo.br/pdf/soc/n15/a12v8n15.pdf . 15 nov. 2018.

SILVA, C.N.; DUTRA, P.V.; LANZA, F. A Relação entre Manifestações Religiosas e o Exercício Profissional dos Assistentes Sociais: Um Estudo das Contradições e Possibilidades no Norte do Paraná. Sociedade em Debate, Pelotas, v. 22, n. 2, p. 415-441, 2016. Disponível em: http://revistas.ucpel.tche.br/index.php/rsd/article/view/1420/944. Acesso em: 15 nov. 2018.

SILVA, C.N.; LANZA, F. Manifestações culturais contemporâneas: a participação de jovens em movimentos religiosos de natureza pentecostal. Anais VII Congresso Português de Sociologia, 19 a 22 jun. 2012. p. 1-13. Disponível em:

http://historico.aps.pt/vii_congresso/papers/finais/PAP1318_ed.pdf. Acesso em: 6 nov. 2018.

SILVA, C.N.; TERUEL, J.M.; SILVA, A.T. Manifestações Religiosas no Espaço Acadêmico: Interferências no Processo Pedagógico. Rev. Ens. Educ. Cienc. Human., v. 18, n.2, 2017. p. 163-168. Disponível em:

http://www.pgsskroton.com.br/seer/index.php/ensino/article/view/4190/3576. Acesso em: 15 nov. 2018.

TRAGTENBERG, M. Introdução à edição brasileira. Max Weber: metodologia das ciências sociais. 3. ed. São Paulo: Cortez Editora; Campinas: Ed. Universidade Estadual de Campinas, 1999. p. xi-I

TRAGTENBERG, M. Max Weber (1864-1920), vida e obra. Os Pensadores. Maurício Tragtenber (Org.). 2. ed. São Paulo: Abril Cultural, 1980. p.vi-xxiv

WEBER, M. A ética protestante e o espírito do capitalismo. São Paulo: Cia das Letras, 2004 .

WEBER, M. Economia e Sociedade. 4. ed. São Paulo: Ed. UNB, Brasília; São Paulo: Imprensa Oficial, 2004. (capítulo 1: Conceitos Sociológicos Fundamentais).

WEBER, M. A "objetividade" do conhecimento nas Ciências Sociais. In: COHN, Gabriel. (Org.). Weber. 3. ed. São Paulo: Ática, 1986. p. 79-127. 


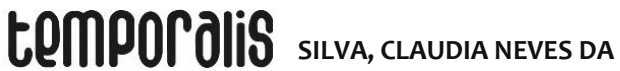

WEBER, M. História Geral da Economia. Os Pensadores. Maurício Tragtenber (Org.). 2 ed. São Paulo: Abril Cultural, 1980. p. 123-178.

WEISS, R. Max Weber e o problema dos valores: as justificativas para a neutralidade axiológica. Rev. Sociol. Polit., v. 22, n. 49, p. 113-137, mar. 2014. Disponível em: http://www.scielo.br/pdf/rsocp/v22n49/07.pdf. Acesso em: 5 out. e 2 nov. 2018.

\section{Cláudia Neves da Silva}

Doutora em História (UNESP - Assis/SP). Professora Associada do Departamento de Serviço Social e do Programa de Pós-Graduação em Política Social e Serviço Social da Universidade Estadual de Londrina (UEL). Membro do Laboratório de Estudos sobre as Religiões e Religiosidades. 